\title{
People and places
}

\section{Notes on the Lundbeck Teaching Fellowship in Chile 1991}

\author{
TOM HARRison, Consultant Psychiatrist, Hollymoor Hospital, Northfield, Birmingham \\ B31 5EX; and AleXandra EsPejo, Trainee Clinical Psychologist, Clinical Psychology \\ Department, University of Sheffield
}

In 1991 the Royal College of Psychiatrists organised two overseas teaching fellowships. In this paper we describe our visit to El Peral Hospital in Chile and discuss the value of our going there.

\section{El Peral Hospital}

The hospital houses 640 people with severe learning difficulties, chronic mental illness, physical disabilities, and epilepsy. In spite of valiant efforts made by overstretched staff the conditions in the best wards remained rudimentary, and in the worst they numbed the senses.

The children's 'pabellon' was the most distressing. Its 50 residents mainly having challenging behaviours and the five ward staff struggle to provide humane care. Resort has to be made to restraints. One child was straight-jacketed to prevent him from shredding his clothes and bedding; another three were strapped by one leg to pillars in the courtyard where they lie or sit in their own excrement.

The use of special needs teachers appeared particularly valuable. They were originally provided for the children with learning difficulties but the service was later extended to the adult population. The teachers organise trips and picnics, alongside more regular educational sessions.

\section{The visit}

We worked in two ways: learning about local practice and sharing information about rehabilitation. We developed a great respect for the staff's enthusiasm, knowledge and eagerness to assimilate new ideas. Improvements continue: a 24 hour on-call rota for medical staff has started and a new 'pabellon' has been completed. Subsequent correspondence revealed that our visit was viewed in a favourable manner, with great warmth expressed towards us. However, staff at the hospital questioned the value of such a visit when it resulted in no practical change.

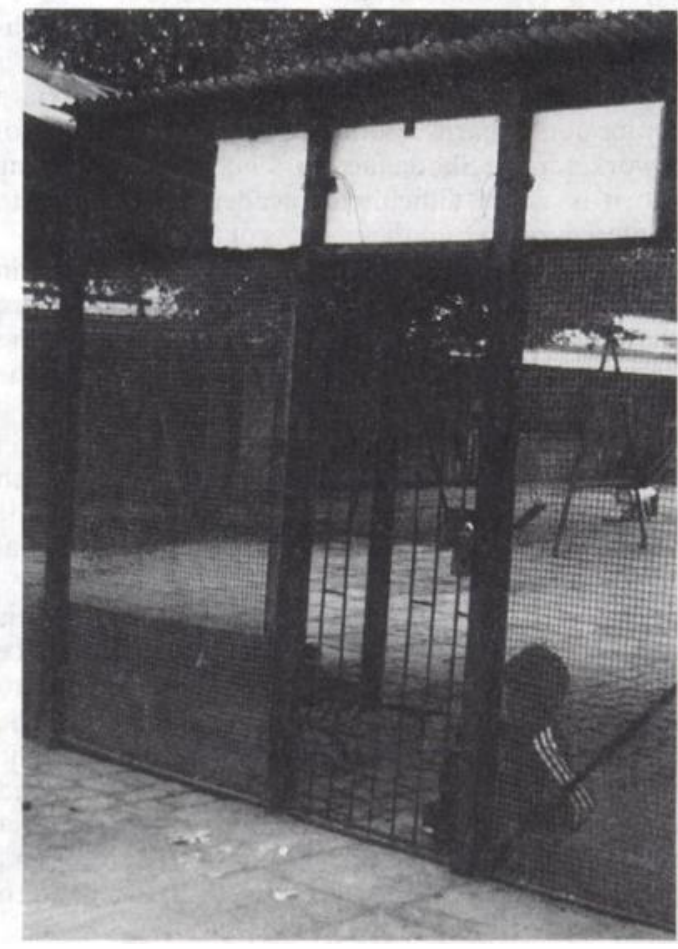

The Children's Unit - looking into the courtyard.

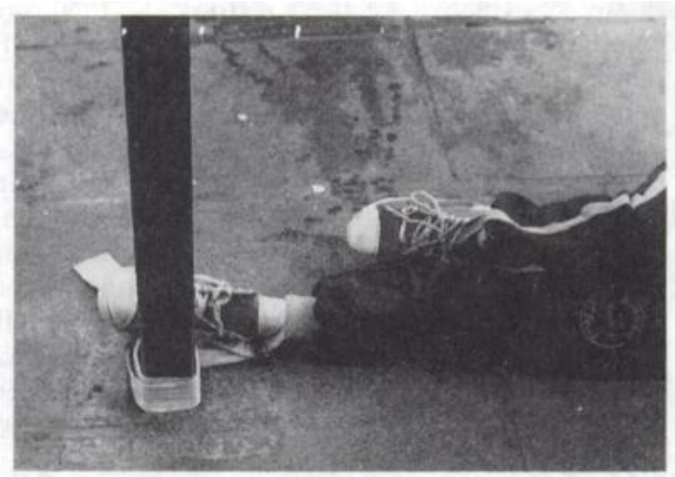

The Children's Unit-a form of restraint. 


\section{Reflections}

A number of issues arise from such a visit. First is the potentially demoralising effect of describing high quality British services to poorly paid staff in meagrely resourced facilities; we may simply be encouraging staff to leave. Second, there is the tendency of the visitor from a better resourced service to overlook the courage and achievements of those staff. The improvements already made at El Peral are remarkable and yet, for example, when writing an earlier draft of this paper we failed to recognise them. Third, there is the emotional impact of this direct experience of severe human deprivation on a visitor. In the UK patient care is usually of an acceptable standard and within an acceptable legal framework. To be exposed to a situation where this is absent is shocking.

\section{Conclusions}

A single visit such as this can only be of restricted value unless it is enhanced by other activities such as fund raising, organising reciprocal visits and training in this country, and developing new links. We believe subsequent teaching fellowships should further support this initial and limited effort, developing from the experience so far gained.

\section{Acknowledgements}

The authors gratefully acknowledge the generosity of many Chilenos in England and Chile, the Royal College of Psychiatrists, and Lundbeck Ltd.

\section{Family Work for Schizophrenia A Practical Guide}

\section{By LIZ KUIPERS, JULIAN LEFF and DOMINIC LAM}

This is a detailed manual of instructions for family work, written by three authors who have developed a course for teaching their approach to working with families of schizophrenic patients. Practical issues are outlined, such as engaging the family, treading the fine line between therapist and guest in the family's home, and teaching the family a problem-solving approach. Dealing with the relatives' emotional responses, the various approaches for different

types of household, and cultural issues are also covered.

Price $£ 10.00,128 p p .$, ISBN 0902241494

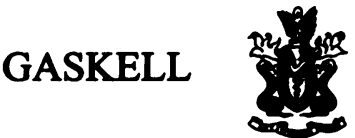

Royal College of Psychiatrists 